\title{
Slot Cut Ultra Wide Band Antennas
}

\author{
Ami A. Desai \\ PG student, Department of \\ EXTC \\ DJ Sanghvi College of \\ Engineering \\ Vile Parle (W) Mumbai, India
}

\author{
Saleha A. Shaikh \\ PG student, Department of \\ EXTC \\ DJ Sanghvi College of \\ Engineering \\ Vile Parle (W) Mumbai, India
}

\author{
Amit A. Deshmukh \\ Professor and Head, \\ Department of EXTC \\ DJ Sanghvi College of \\ Engineering \\ Vile Parle (W) Mumbai, India
}

\begin{abstract}
The ultra wide band antennas are required in applications where larger bandwidth for the transmitting signal is needed. They cover wide bandwidth in the range from 500 $\mathrm{MHz}$ to the frequencies above $8000 \mathrm{MHz}$. In this paper, a review of various techniques to realize ultra wide band microstrip antennas (MSA) is presented. They are realized by using different techniques like basic planar monopole antenna and the variations of the same by using different shapes of radiating monopole antenna, like, bi-conical, Bowtie, etc. They are also realized by using modifying the feeding strip shape or by cutting the slot inside the patch. The ultra wide band (UWB) response has also been realized by using fractal shapes in the radiating monopole antenna. Towards the end of paper, the scope of future work is proposed, wherein the exact formulation of resonant length is needed for planar monopole antenna at its fundamental and higher order modes as well as the explanation for the ultra wide band response in terms of operating modes in slot cut and fractal geometries.
\end{abstract}

\section{Keywords}

Ultra wide band microstrip antenna, planar monopole antenna, slot cut Ultra wide band microstrip antenna, Fractal microstrip antenna.

\section{INTRODUCTION}

Since federal communication commission (FCC) declared 3.1-10.6 GHz as ultra wide band frequency range, there have been many UWB antenna studies. Recently, in UWB application, monopoles of various configurations have attracted more and more attentions because of their attractive merits, such as nearly omnidirectional radiation patterns, simple structure and low cost. Recently, due to the miniaturization of the personal communication devices, the need of compact antennas has become a necessity. Moreover, the growth of wireless systems operating in multiple independent bands or wide bands leads to the use of multi-functional antennas such as UWB. Due to their capabilities for high data rate information transmission, ultra-wide band communication systems are highly promising. In addition, these systems have low power consumption and low interference and immunity to multipath fading.

\section{PLANAR MONOPOLE UWB}

\section{ANTENNA}

The configuration shown in Fig 1[1] is a planar monopole antenna. Thicker substrate with lower dielectric constant results in increase in the BW of MSA up to $10 \%$. The large $h$ increases the probe inductance, and the input impedance becomes too inductive to obtain impedance matching. The MSAs with edge probe feeding are used to avoid impedance mismatch. The formula for rectangular microstrip antenna (RMSA), to calculate resonance frequency is given by [1]:

$$
\mathrm{f}_{0}=\frac{c}{2 \sqrt{\epsilon r e}} \sqrt{\left(\frac{m}{L e}\right)^{2}+\left(\frac{n}{W e}\right)^{2}}
$$

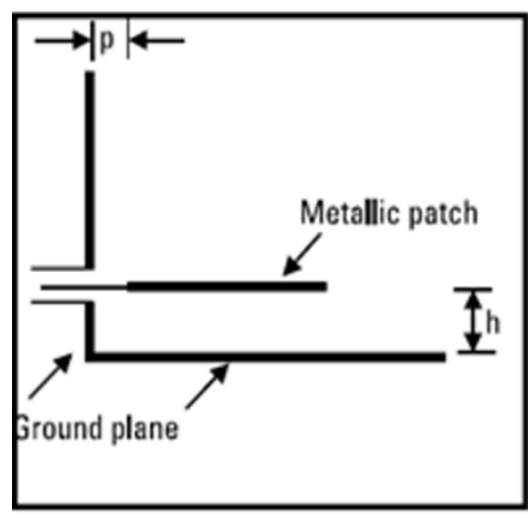

Fig.1: Planar Monopole Antenna [1]

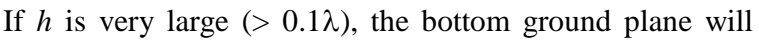
have a negligible effect and hence can be removed. Therefore, for a large $h$ tending to infinity, the MSA configuration reduces to that of a planar monopole antenna which acts as a quarter wavelength resonator.

For planar monopole,

$$
\begin{gathered}
f_{0}=c /(4 L e)\left(\text { since, } \varepsilon_{r}=1\right) \\
L_{e}=L+\Delta L+p
\end{gathered}
$$




\section{SLOT CUT UWB ANTENNAS}

Slot antennas are currently under consideration for use in UWB systems due to the attractive advantages such as low profile, light weight, ease of fabrication and wide frequency bandwidth. This type of antenna has been realized by using microstrip line and CPW feeding structures.

\subsection{Arrow Shaped UWB Antenna}

The arrow shaped UWB antenna is shown in Fig.2 [2]. An UWB antenna radiating at $3-15 \mathrm{GHz}$ is designed. The antenna is designed using a dielectric material which size of $41 \times 36 \mathrm{~mm}$. The dielectric constant of the material is $\varepsilon=6$, 15 and the thickness is $\mathrm{t}=0,508 \mathrm{~mm}$. The arrow shaped patch is fed by a strip line. The dimensions of antenna are as given: $D 1=D 2=10 \mathrm{~mm}, \mathrm{D} 3=23 \mathrm{~mm}, \mathrm{D} 4=5 \mathrm{~mm}, \mathrm{D} 5=31.5$ and $\mathrm{R}=3.5 \mathrm{~mm}$. The RCS (radar cross section) of the antenna is reduced by modifying the geometry of the antenna. Simulation results in Fig.3 [2] shows that, when the electric field of the incident wave is in $\mathrm{x}$ direction, RCS of the antenna reduced about $10 \mathrm{~dB}$. RCS is reduced up to $25 \mathrm{~dB}$ at $5 \mathrm{GHz}$. When the electric field of the incident field is in y direction, RCS of the antenna is reduced about $10 \mathrm{~dB}$ at the frequencies higher than $10 \mathrm{GHz}$. RCS of the antenna is reduced up to $25 \mathrm{~dB}$ [2].

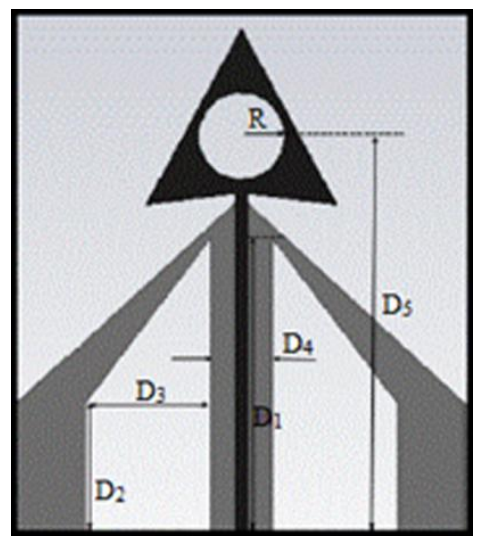

Fig.2: Arrow shaped UWB antenna [2]

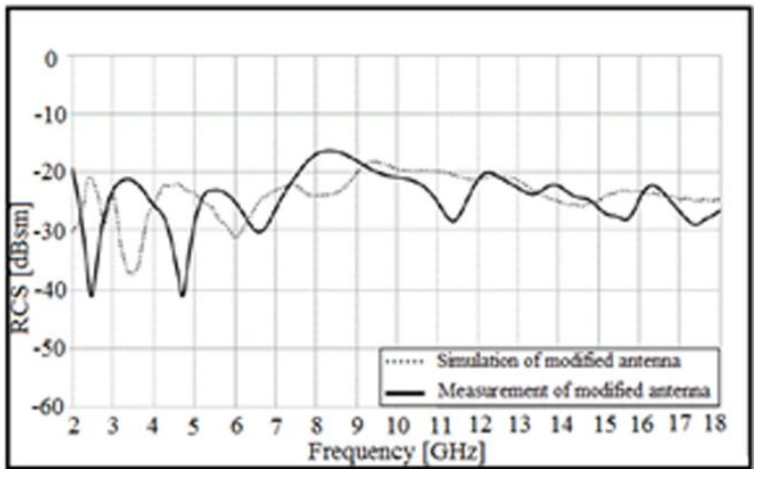

Fig 3: Simulated and measured results of the modified antenna [2]

\subsection{Octagonal Shaped UWB Antenna}

An octagonal shaped UWB antenna is shown in Fig.4 [3]. The antenna radiates at $2.5-18 \mathrm{GHz}$ with the fractional bandwidth of about $150 \%$. The size of antenna is $60 \times 70$ $\mathrm{mm}$. The dielectric constant of the material is $€=6.15$ and the thickness is $t=1.27 \mathrm{~mm}$. In order to reduce RCS (radar cross section), some modifications are made of the reference antenna. The radius of the elliptic geometry at $y$ axis is $E_{y}=29 m m$ and $x$ axis is $E_{x}=35 \mathrm{~mm}$ and a circular shape with $R=24 \mathrm{~mm}$ is extracted from the patch.

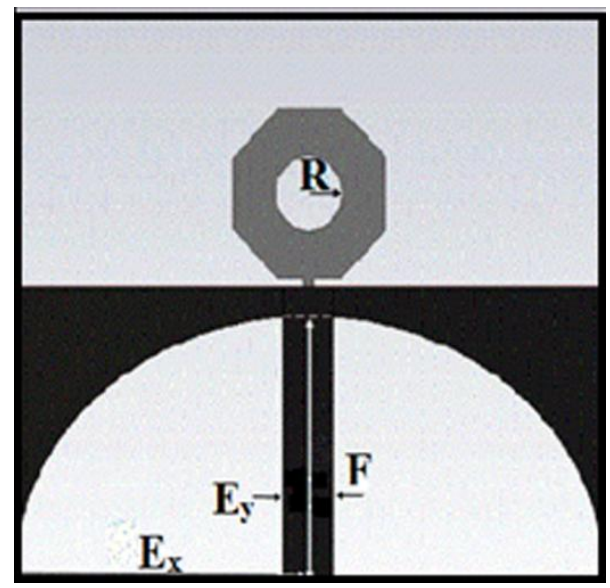

Fig 4: Octagonal Shaped UWB Antenna [3]

A strip line which is located on the ground layer is used to feed the patch. In order to make modifications of the geometry, an elliptic geometry is extracted from the ground layer. The origin of the elliptic geometry is on the middle of the feeding edge of the antenna. When the electric field of the incident wave is in $\mathrm{x}$ direction, RCS of the antenna reduced about $10 \mathrm{~dB}$. Especially at $4.5 \mathrm{GHz}$ it's reduced up to $25 \mathrm{~dB}$. When the electric field of the incident field is in $\mathrm{y}$ direction, RCS of the antenna is reduced about $10 \mathrm{~dB}$ at 4.5-18GHz. As shown in Fig.7 [3] RCS of the antenna is reduced up to $25 \mathrm{~dB}$ [3].

\subsection{Volcano Smoke Planar UWB Antenna}

The volcano smoke planar printed circuits antenna is shown in Fig 5 [4]. The antenna is fed using coplanar waveguide. The dimensions of antenna are as given: $\mathrm{H}=75 \mathrm{~mm}, \mathrm{~W}=75$ $\mathrm{mm}$, the central conductor strip width is $\mathrm{W}_{\mathrm{l}}=2 \mathrm{~mm}$, the slot width is $\mathrm{S}=1 \mathrm{~mm}$, the radius of top arc of the antenna is $\mathrm{R}_{\mathrm{l}}=20 \mathrm{~mm}$, the radius of both side arc of the antenna is $\mathrm{R}_{2}=18 \mathrm{~mm}$, and $\mathrm{H}_{2}=10 \mathrm{~mm}$, the neck radius of antenna is $\mathrm{R}=47.3 \mathrm{~mm}$. The six resistances on both sides of the antenna are all $150 \Omega$, however the top resistance is changed when the resistance loop circuit is loaded and the $S_{11}$ value corresponding to the resistance is measured. Since the loop circuit is not connected and due to the coupling of five segment printed circuit with the antenna, stop bands are formed. When the antenna is loaded with loop circuit and without resistance, the value of $S_{n}$ which is above-10db appears to be at two stop bands. The loading of antenna with appropriate resistance shows that the lower cut-off 
frequency of bandwidth expands significantly. Planar antenna fed via the co-planar waveguide has wide bandwidth and after loading the resistance loop circuit, the bandwidth will become wider. Comparison of $\mathrm{S}_{11}$ of the antenna in three cases is shown in Fig 6 [4].

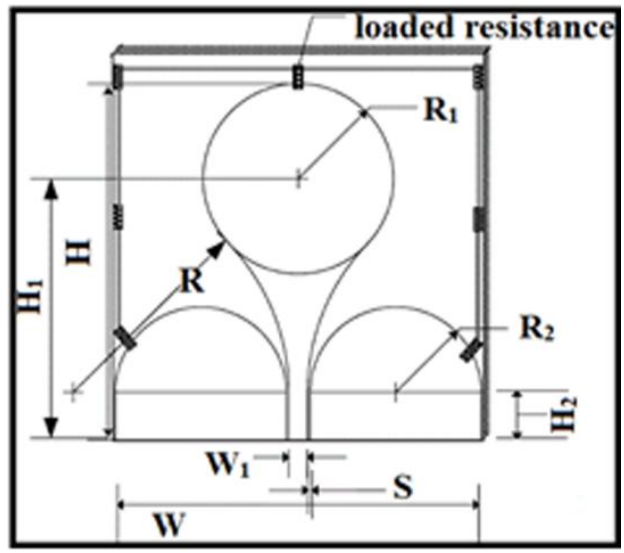

Fig 5: Volcano Smoke Planar UWB Antenna [4]

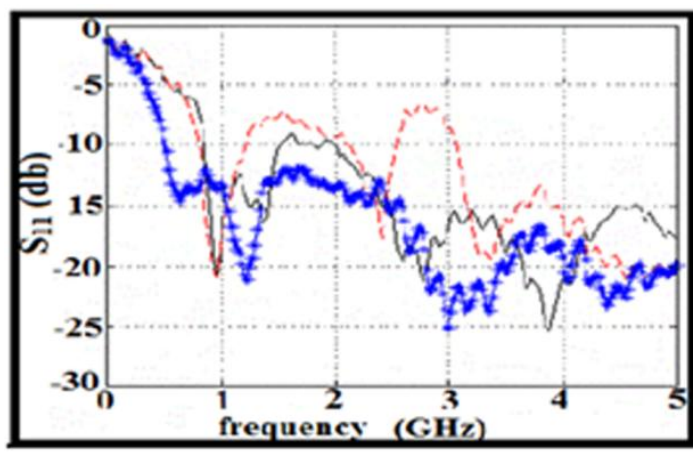

Fig 6: ( - ) without resistance and loop circuit (-----) with loop circuits and without resistance (*) with resistance and loop circuits

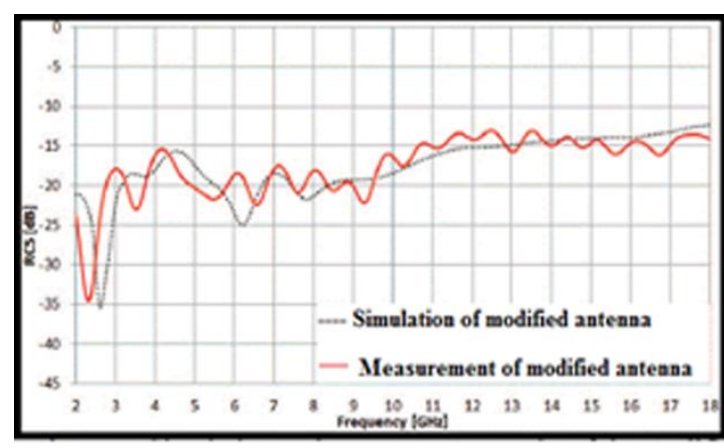

Fig 7: Simulated and measured results of modified antenna [3]

\subsection{Multiple Stopbands UWB Antenna}

The structure of the CPW-fed circular monopole multiple Stopbands UWB antenna is shown in Fig. 8 [5]. The CPW feed line is connected with all three pairs of quarter wavelength L-shape resonance slots. A single layer substrate with the relative permittivity 2.65 and the thickness of $1 \mathrm{~mm}$ is used. The dimensions of the antenna are as shown in Fig.8. Three stop bands at $2.4 \mathrm{GHz}, 3.5 \mathrm{GHz}$ and $5.8 \mathrm{GHz}$ are observed in Fig. 9 [5] due the three quarter wavelength $\mathrm{L}$-shape slots respectively.

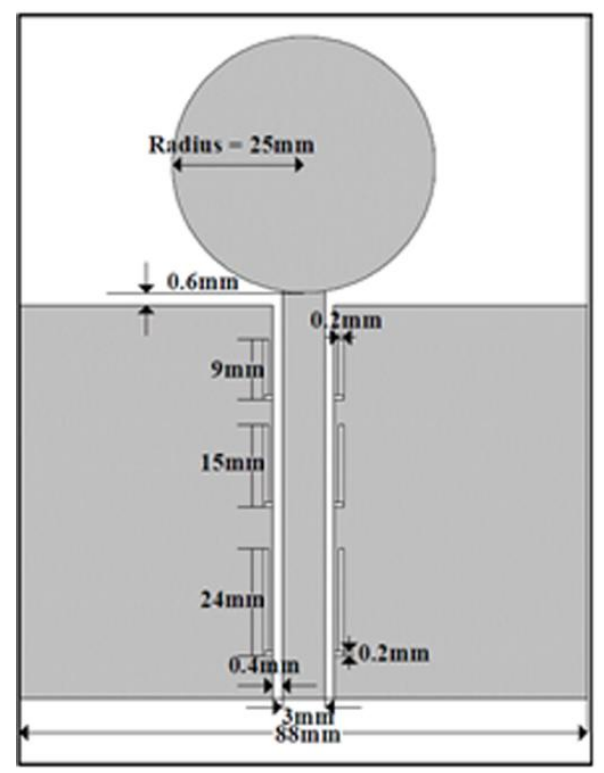

Fig 8: Multiple Stopbands Ultra Wide Band Antenna [5]

The radiation patterns are also measured in microwave anechoic chamber at $2 \mathrm{GHz}, 3.1 \mathrm{GHz}$ and $4.6 \mathrm{GHz}$. Within the passband the antenna has nearly omni-directional radiation patterns. The antenna has the impedance bandwidth defined by $\mathrm{S}_{11}<-10 \mathrm{~dB}$ from $1 \mathrm{GHz}$ to $6 \mathrm{GHz}$ and has three stopbands at $2.4 \mathrm{GHz}, 3.5 \mathrm{GHz}$ and $5.8 \mathrm{GHz}$ respectively.

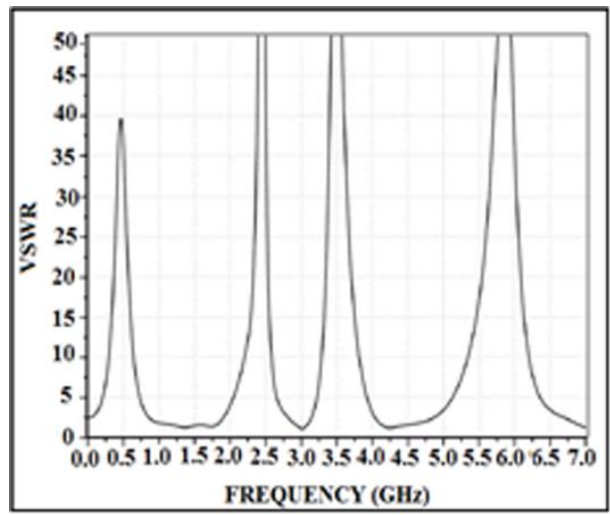

Fig 9 : Simulated VSWR [5] 


\subsection{Band Notched UWB Antenna}

A band notched UWB antenna is shown in Fig.10 [6]. A semicircular wide slot antenna fed using circular microstrip line operates with a band-notched frequency at $5 \mathrm{GHz}$. The band-notched operation is achieved by using a U-slot in the circular microstrip patch. It is constructed on a rectangle substrate with relative permittivity of 2.65 and thickness of $1 \mathrm{~mm}$ with length and width of $80 \mathrm{~mm}$ and $50 \mathrm{~mm}$, respectively. The dimensions of the antenna are as shown in Fig.10 [6]. The antenna can generate a wide operating

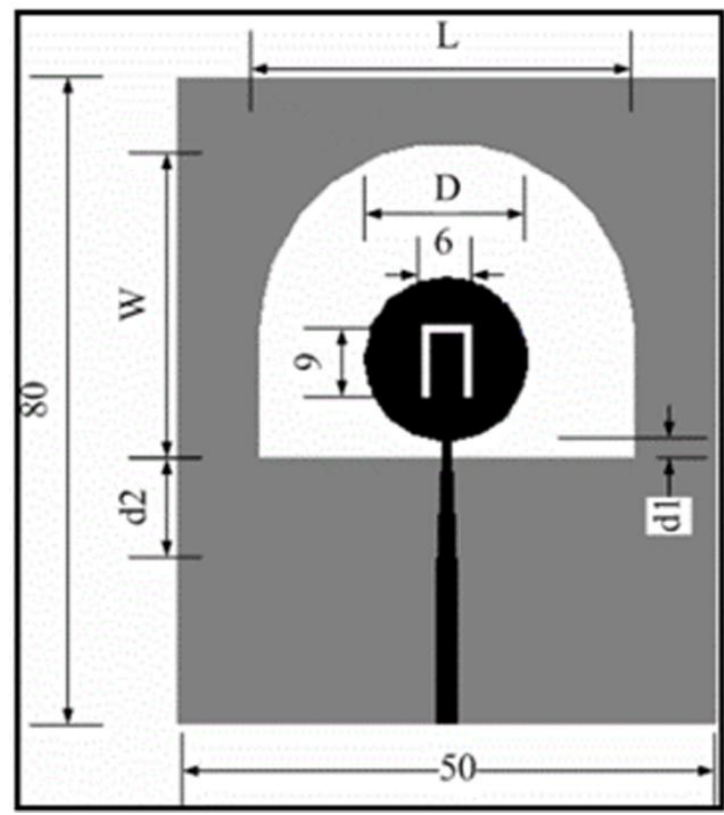

Fig 10 : Geometry of band notched UWB antenna [5]

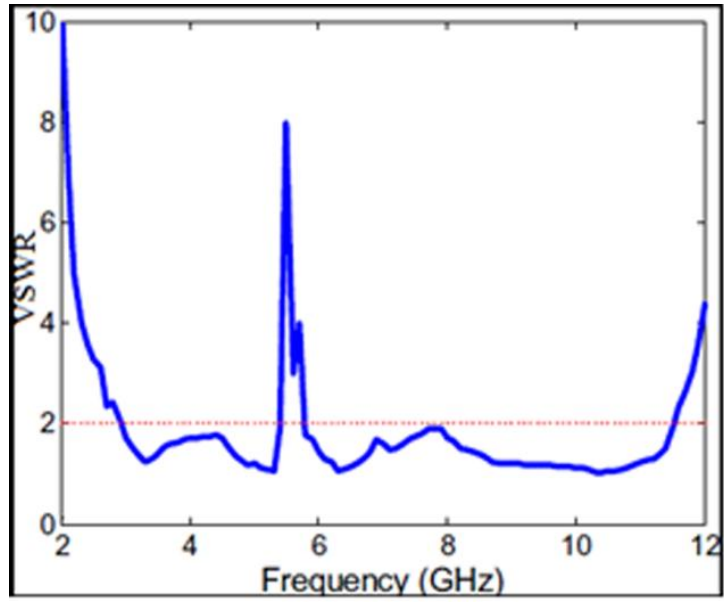

Fig 11: The amplitude characteristic of field distribution for $1 \mathrm{GHz}$ [5] bandwidth of 3.1-10.6 GHz covering the UWB. However by cutting a narrow $\mathrm{U}$ slot (width $1 \mathrm{~mm}$ ) inside the circular patch, a notched frequency band for the UWB slot antenna can be achieved. In this case the antenna becomes nonresponsive at that frequency band, leading to a band notched UWB operation. For the proposed antenna, a sharp, band notched operation is achieved in the $5 \mathrm{GHz}$ band, as shown in Fig.11 [6] with small effects on other frequencies in the UWB bandwidth observed [6].

\subsection{Rectangular Wide Slot Band Rejection UWB Antenna}

A wide slot antenna with fork-shaped microstrip line fed is shown in Fig.12 [7]. The dimensions of antenna are as shown below in Fig.12 [7]. The bandwidth of a wide slot is intrinsically large. A fork like tuning stub is added so as to expand the impedance bandwidth of the antenna.

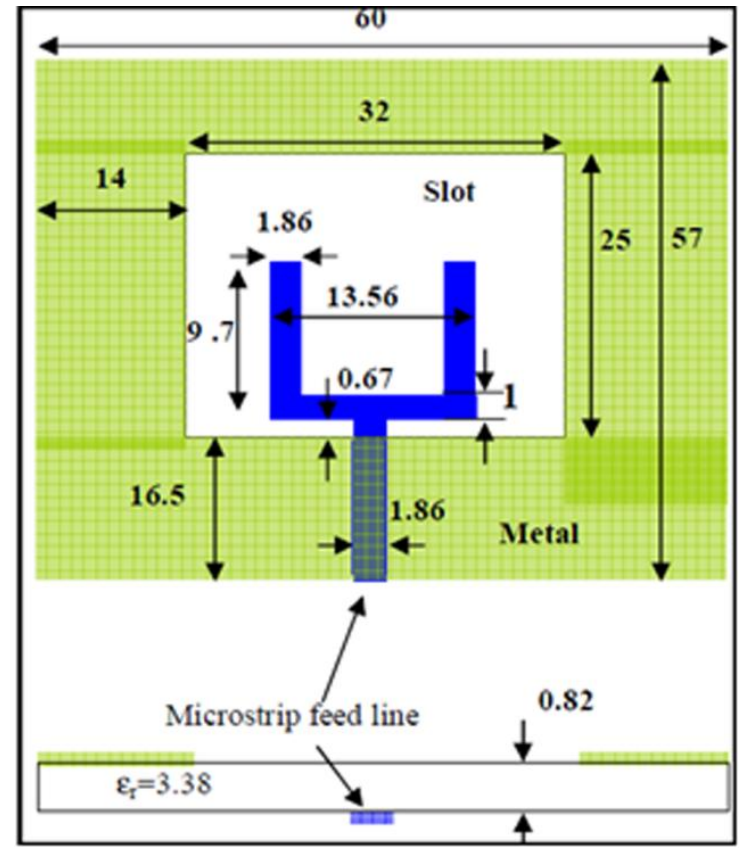

Fig 12: Rectangular wide slot geometry [7]

A limited ground plane is added to this antenna to obtain a directive antenna.Fig.13 [7] shows measured the gain of the directional wide slot antenna. However, the results show that the antenna has a bandwidth where the gain is low. Hence it is necessary to reject this little bandwidth. The bandwidth rejection is achieved with open stub or notch/slot. The solution consists of placing a C-resonant strip on the radiating slot, in front of the fork-shaped tuning stub as shown in Fig.14 [7]. The length of C-strip is a half wavelength at centre frequency of the desired rejected bandwidth. The bandwidth is controlled by the width of the strip. 


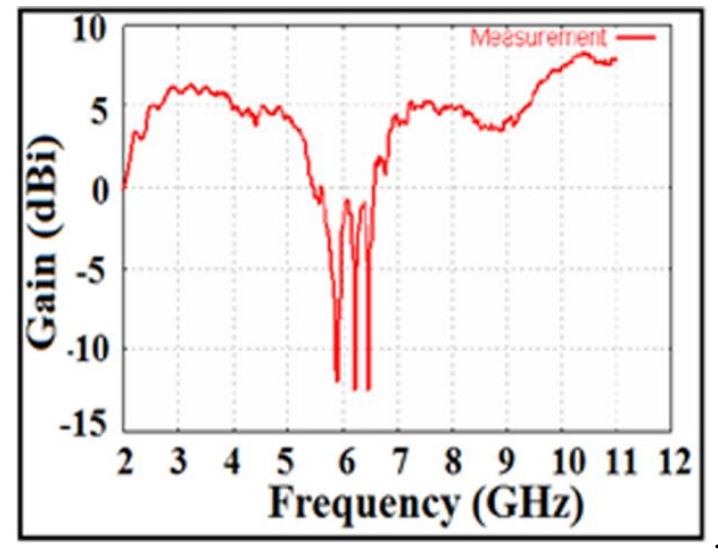

Fig 13: Gain of directional wide slot antenna [7]

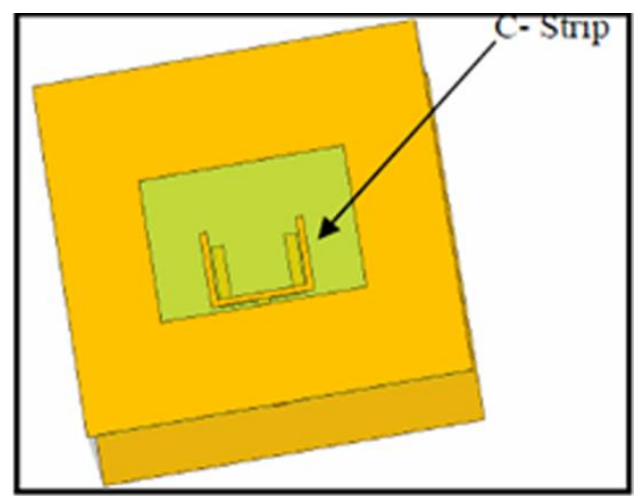

Fig 14: Directional wide slot antenna geometry with C-strip in front of the fork-shaped tuning stub [7]

The placement of the C-strip helps in achieving the objective of rejecting the 5 to $6 \mathrm{GHz}$ bandwidth as shown in Fig.15 [7].

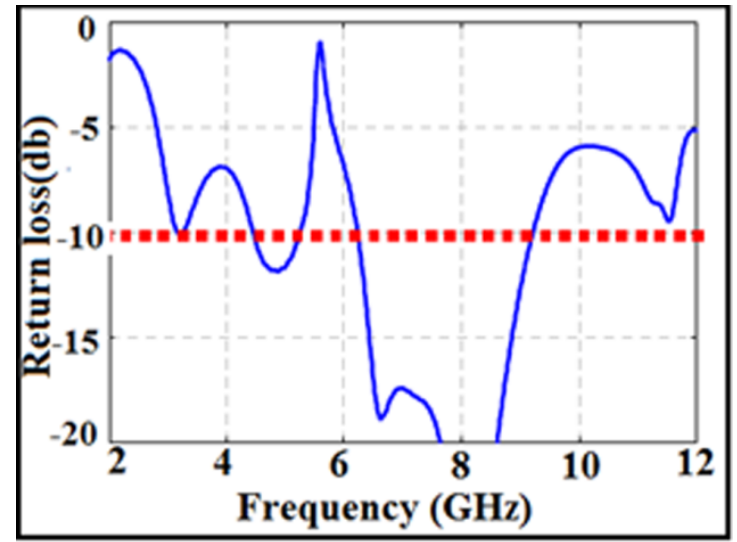

Fig 15: Simulated return loss of directional wide slot antenna geometry with C-strip in front of the fork shaped tuning stub.[7]

\section{CONCLUSION AND SCOPE OF FUTURE WORK}

This paper briefly reviews, slot cut ultra wide band (UWB) antenna. It summarizes various benefits of using UWB such as bandwidth enhancement, reduced radar cross section, band rejection. The exact formulation of resonant length that is needed for planar monopole antenna at its fundamental and higher order modes and analysis of UWB response in terms of operating modes of slot cut and fractal geometries which has not been reported in the papers reviewed will be explored in future research work.

\section{REFERENCES}

[1] Kumar, G. and Ray, K. P. 2003. Broadband Microstrip Antenna

[2] Cengizham, M. D., Sibel, C. and Gonca, C. 2013. An Arrow shaped Ultra Wide Band Antenna With Reduced RCS , IEEE Jordan Conference on Applied Electrical Engineering and computing technologies (AEECT)

[3] Cengizham, M. D., Sibel, C. and Gonca, C. 2013. An Octagonal Shaped Ultra Wide Band Antenna With Reduced RCS , second International Japan-Egypt conference on electronics, Communications and Computers (JEC-ECC)

[4] Li, C., Zhang, Y., Li, Y., Wang, S. and Liao, X. 2011. Volcano Smoke Planar Ultra-Wide Band Antenna, International Conference on Electronic \& Mechanical Engineering and Information Technology

[5] Chen, Y., Wei, H. and Zhenqi, K. 2008. Multiple Stopbands Ultra Wide Band Antenna, ICMMT Proceedings

[6] Yuan, Y., and Zhenghe, F. 2006. A Novel BandNotched Ultra-Wideband Microstrip-Line Fed WideSlot Antenna, Proceedings of Asia-Pacific Microwave Conference

[7] Begaud, X. Ultra Wideband Wide Slot Antenna With Band-Rejection Characteristics. 